\title{
On the evolution of monopoly pricing in Internet-assisted search markets
}

Article

Accepted Version

García-Gallego, A., Georgantzis, N., Jaramillo-Gutiérrez, A., Pereira, P. and Pernias-Cerrillo, J. C. (2014) On the evolution of monopoly pricing in Internet-assisted search markets. Journal of Business Research, 67 (5). pp. 795-801. ISSN 0148-2963 doi: https://doi.org/10.1016/j.jbusres.2013.11.047 Available at https://centaur.reading.ac.uk/35713/

It is advisable to refer to the publisher's version if you intend to cite from the work. See Guidance on citing.

Published version at: http://dx.doi.org/10.1016/j.jbusres.2013.11.047

To link to this article DOI: http://dx.doi.org/10.1016/j.jbusres.2013.11.047

Publisher: Elsevier

All outputs in CentAUR are protected by Intellectual Property Rights law, including copyright law. Copyright and IPR is retained by the creators or other copyright holders. Terms and conditions for use of this material are defined in the End User Agreement.

\section{www.reading.ac.uk/centaur}

\section{CentAUR}

Central Archive at the University of Reading 
Reading's research outputs online 


\section{On the evolution of monopoly pricing in Internet-assisted search markets}

Aurora García-Gallego, LEE and Economics Department, U. Jaume I, Spain

Nikolaos Georgantzís, LEE and Economics Department, U. Jaume I, Spain

Ainhoa Jaramillo-Gutiérrez, ERICES and D. of Applied Economics, U. of Valencia

Pedro Pereira, Autoridade da Concorrencia and CEFAGE-UE U. of Evora, Portugal

J. Carlos Pernías-Cerrillo, Economics Department, U. Jaume I, Spain

August, 2013

The authors gratefully acknowledge financial support by the Ministerio de

Economía y Competitividad (ECO2011-23634), UJI (P1-1B2010-17) and P. de

Excelencia de la Junta de Andalucía (P07-SEJ-03155). This paper benefitted from

extremely helpful comments by E. Hopkins and M. Sefton. Correspondence to: A.

García-Gallego, Economics Dpt., U. Jaume I, Av. Sos Baynat s/n, 12071-Castellón,

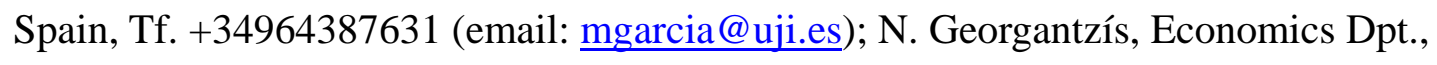

U. Jaume I, Av. Sos Baynat s/n, 12071-Castellón, Spain, Tf. +34964387628 (email:

georgant@uji.es); A. Jaramillo-Gutiérrez, Dpt. of Applied Economics, U. of Valencia, Av. Tarongers s/n, 46022-Valencia, Valencia, Spain, Tf. +34963828407 (email:

Ainhoa.Jaramillo@uv.es); P. Pereira, Autoridade da Concorrencia, Rua Laura Alves 4, 7º 1050-138, Lisboa Portugal (email: pedro.br.pereira@gmail.com); J.C. 
Pernías-Cerrillo Economics Dpt., U. Jaume I, Av. Sos Baynat s/n, 12071-Castellón, Spain, Tf. +34964387164 (email: pernias@eco.uji.es)

\begin{abstract}
This paper studies the evolution of prices in markets with price-comparison engines. We analyze laboratory data under two industry sizes and two conditions concerning the sample (complete, incomplete) of prices available to informed consumers. Distributions are typically bimodal. One of the two modes, corresponding to monopoly prices, tends to increasingly attract prices over time. The second one, corresponding to interior prices, presents a decreasing trend. Monopoly pricing can be an insurance against more competitive (but riskier) behavior. In fact, subjects earning low profits due to interior pricing in the past are more likely to choose monopoly pricing.
\end{abstract}

Keywords: Internet Economics; Price-Comparison Search Engines; Mixed Strategy Equilibria; Experimental Economics. 


\section{Introduction}

Despite the competition-enhancing effect of Price-Comparison search engines

on the Internet, price dispersion in virtual search markets is systematic and persistent.

This paper studies whether those prices will converge towards some stable

distribution. We obtain two attractors of pricing strategies: the monopoly price, and

more competitive pricing. One main finding is that the frequency of monopoly pricing appears to have a systematically increasing trend, whereas competitive prices decline over time.

According to Diamond (1971), the existence of captive consumers may be sufficient for monopoly pricing to emerge in non-monopolistic homogeneous good markets. Subsequently, Varian (1980), Rosenthal (1980), Burdett and Judd (1983) and Stahl (1989) extended the theory. Mixed strategy equilibria render these models compatible with price dispersion in search markets. Along this line, Baye and Morgan (2001), Brynjolfsson and Smith (2000), Iyer and Pazgal (2000) and Kocas and Kiyak (2006) pay special attention to the role of the Internet. Morgan, Orzen and Sefton (2006) report experimental results confirming the basic comparative statics prediction of the Varian (1980) model. Also, Orzen (2008) offers some evidence for the conjecture by Janssen and Moraga-González (2004) concerning the collusive-pricing 
attractor which tends to reverse Varian’s (1980) comparative statics prediction regarding the size of an industry.

Some theoretical papers study the dynamic properties of price distributions in consumer search markets. Hopkins and Seymour (2002) show that a broad family of learning dynamics may be stable under sufficient ignorance. Benaïm, Hofbauer and Hopkins (2009), referring to Shapley (1964) best-response cycles, show that price time averages may converge to Nash even under unstable price dispersions.

Cason and Datta (2006), Cason and Friedman (2003) and Cason, Friedman and Wagener (2005) have paid attention to the dynamics of price dispersion.

Especially, the Edgeworth cycles in Cason et al. (2005) are evidence for the instability of price dispersion prediction in Hopkins and Seymour (2002). Also, the serial correlation of individual in Cason and Friedman (2003) can be evidence against the hypothesis of mixed strategy play.

Finally, while Varian (1980) predicts agglomeration on monopoly pricing as a result of rational behavior, Baye and Morgan (2004) directly relate the frequency of monopoly pricing to the level of bounded rationality in the market. Observe that competitive pricing involves some probability of a higher profit but also the risk of a lower one. 
In our experiment, contrary to the majority of previous studies ${ }^{1}$, subjects face a simulator of rival behavior following equilibrium distributions. Thus, deviations from equilibrium cannot be the result of learning among interacting agents. Two dynamic patterns occur parallel to each other. The two patterns concern two alternative peaks of typically bimodal price distributions. The first peak is the interior pricing mode, whereas the second is the monopoly pricing one. The dynamics affecting the two modes occur in opposite directions. Each one of the corresponding patterns remains invariant across different experimental conditions. The paper contains the following sections: Section 2 outlines the theoretical framework. Section 3 describes the experimental design. Section 4 reports the results and section 5 concludes.

\section{Theoretical framework}

Consider a market for a homogeneous search good that opens for one period. There is a price comparison search engine, $n \geq 3$ vendors, indexed through $j=1, \ldots, n$, and many consumers. The Price-Comparison Search Engine, lists the firms in its Index, and the prices they charge. Denote by $k$ the number of vendors on the price-comparison search engine. We refer with $k$ to the Size of the Index. The search engine has Complete Coverage if it indexes all vendors present in the market: $k=n$. If

${ }^{1}$ Cason and Datta (2006) adopt a similar strategy, but they simulate optimal consumer search behavior. 
$k<n$, the search engine has Incomplete Coverage and indexes each of the $n$ vendors

with the same probability $k / n .^{2}$

There is a unit measure continuum of risk neutral consumers. Each consumer

has a unit demand, and a reservation price of 1 . There are 2 types of consumers.

Non-Shoppers, a proportion $\lambda \in(0,1)$ of the consumer population, do not use the price-comparison search engine. The other consumers, a proportion 1- $\lambda$, are Shoppers and use the price-comparison search engine.

Prices cannot exceed 1 , and shoppers buy a unit of the product from the cheapest seller on the engine whereas they split equally among sellers with equal prices. Non-shoppers distribute themselves evenly across vendors.

Vendors are identical with marginal costs equal to zero. They know the probability with which they will be on the index, but do not observe the identity of the other vendors on the index, before choosing prices.

Let $\Pi_{j}(p)$ be the expected profit of vendor $j$ charging a price $p$ on $\mathbb{R}_{0}^{+}$. A vendor's strategy is a cumulative distribution function over prices, $F_{j}(.)^{3}$ A Nash equilibrium is a $n$-tuple $\left\{F_{1}(),. \ldots, F_{n}().\right\}$ of cumulative distribution functions over prices such that for $\Pi_{j}{ }^{*}$ on $\mathbb{R}_{0}^{+}$, and $j=1, \ldots, n, \Pi_{j}(p)=\Pi_{j}{ }^{*}$, for all $p$ on the support of $F_{j}($.$) , and \Pi_{j}(p) \leq \Pi_{j}^{*}$, for all $p$. Denote by $\tau$ the type of the search engine, and let $C(I)$,

\footnotetext{
2 The case of unbiased incomplete coverage is analyzed. A more complete version of the model accounting for biased incomplete coverage can be found in García-Gallego, Georgantzís, Pereira and Pernías (2004).

${ }^{3}$ It is well known that this game has no equilibrium in pure strategies.
} 
mean Complete (Incomplete) Coverage. Then, $\tau$ belongs to $\{C, I\}$. Denote by $\phi_{j}^{\tau}$ the probability of firm $j$ to be on the index, such that $\phi_{j}^{\tau}=k / n$. Ignoring ties, the expected profit of a vendor that charges $p \leq 1$ is:

$$
\Pi_{j}(p)=p \frac{\lambda}{n}+p(1-\lambda) \phi_{j}^{\tau}\left[1-F_{j}^{\tau}(p)\right]^{k-1}
$$

Let $l_{j}^{\tau}$ be the lowest price vendor $j$ is willing to charge to sell to both types of consumers when the search engine has type $\tau$, that is: $l_{j}^{\tau}\left[\lambda / n+(1-\lambda) \phi_{j}^{\tau}\right]-\lambda / n \equiv 0$. Then, in the symmetric equilibrium ${ }^{4}$ :

$$
p \frac{\lambda}{n}+p(1-\lambda) \phi_{j}^{\tau}\left[1-F_{j}^{\tau}(p)\right]^{k-1}=\frac{\lambda}{n}(2)
$$

All vendors are on the index with positive probability, in the sense that there is no vendor whose probability to be on the index is zero. Hence, they face the trade-off of charging the monopoly price to non-shoppers, or charging a low price to attract also shoppers. This leads them to randomize over prices. The price distribution when the market consists of $n$ vendors, and the search engine has an index of size $k \leq n$, is identical to the price distribution when the search engine has Complete Coverage, $k=$ $n$, and the market consists of $k$ vendors: $F^{I}(. ; n, k)=F^{C}(. ; k)$.

Following discussion by García-Gallego et al. (2004), a decrease in the index has two impacts. First, the decrease of index reduces the number of rivals with which a vendor has to compete to sell to shoppers from $k-1$ to $k$-2. Second, the decrease in the size of the index reduces the probability that a certain vendor will be on the index ${ }^{4}$ According to Baye et al. (1992) there is also a continuum of asymmetric equilibria. 
from $k / n$ to $(k-1) / n$. Consequently, the price distribution rotates counter clock-wise, as in Figure 1.

Figure 1 here

\section{Experimental design}

In a market environment like the aforementioned one, we present data from 4 experimental conditions. The 4 treatments (C3, I3, C6, I6) correspond to the combination of two different industry sizes, $n \in\{3,6\}$, with two sizes of the index (Complete, Incomplete). The design is appropriate to test the model's comparative statics predictions concerning the size of the market under complete coverage by comparing a complete coverage triopoly (C3) to a complete coverage hexapoly (C6). By comparison of C3 to I3 and C6 to I6, we test the model's hypotheses concerning the completeness of the index. In fact, both incomplete coverage treatments use a 2/3 probability of being on the index of the search engine. ${ }^{5}$ In all treatments, we set $\lambda$ equal to $1 / 2$.

Table 1 here

Table 1 presents the details of our design and the statistics corresponding to the theoretical price distributions. This helps addressing the following testable hypotheses:

H1: An increase in the number of firms in the market leads to a higher average price.

${ }^{5}$ Thus, in treatment I3 we use $k=2$ and in treatment I6 we set $k=4$. 
H2: An increase in the size of the index leads to a higher average price.

These two hypotheses provide a test for the main prediction of the Burdett and Judd (1983) and Varian (1980) models respectively. The main questions we address in this paper are:

H3: An increase in the number of firms in the market increases the frequency of monopoly pricing.

H4: An increase in the number of indexed firms increases the frequency of monopoly pricing.

As an alternative to these four hypotheses, the conjecture by Janssen and Moraga-González (2004) concerning the collusion-facilitating role of a decrease in the size of the industry tends to reverse the effects predicted here. Regarding the behavior of individual prices over time, the hypothesis of mixed strategy play implies that a firm's pricing strategy in period $t$ is independent from its strategy in period $t+1$ :

H5: A firm’s probability of setting a given price remains invariant over time.

In order to avoid a noisy learning environment ${ }^{6}$ each subject faces a simulator of rival behavior whose prices follow the equilibrium distributions. Specifically, each subject participating in treatments C3 and I3 faces in each period 2 simulated players, whereas each subject in treatments C6 and I6 faces another 5 simulated players. We

${ }^{6}$ Cason and Friedman (2003) and Warnick and Hopkins (2006) warn us on the difficulties arising in experimental tests of mixed strategy equilibria due to the fact that an individual agent is learning in the presence of the noise by rivals’ learning strategies. 
obtain a total of 180 independent observations (a series of 50 period strategies per subject). We ran a total of 10 sessions at the Laboratorio de Economía Experimental (LEE) of the U. Jaume I in Castellón (Spain). In each session, we randomly assign 18 subjects to two different treatments under the same price-sampling condition but with different industry sizes. A total of 180 subjects participate, earning approximately $20 €$ each.

We extracted the simulated prices from the equilibrium distributions, using the inverse transformation method (e.g. Cameron and Trivedi, 2005). ${ }^{7}$ In order to guarantee that heterogeneity can be genuinely attributed to differences across individuals, we maintain invariant the actual realizations of the simulated players within each treatment. ${ }^{8}$

\section{Data analysis and main results}

Table 2 provides descriptive statistics for period average prices and profits. We plot the evolution of these variables on Figures 2 to 4 . We express profits as a proportion of the amount corresponding to monopoly:

$$
\pi_{i t}=\frac{p_{i t} q_{i t}}{\lambda / n_{i}}
$$

where $i$ indexes subjects, $t$ indexes time periods, $p_{i t}$ and $q_{i t}$ are the prices and sales of firm $i$ in period $t$, and $\lambda / n_{i}$ is the profit level that a firm obtains by setting $p=1$ and

\footnotetext{
7 We ran the experiment using specific software in Java.

8 There has been no mention to equilibrium mixed strategy play in the instructions because subjects could interpret this as a sign of correct play, encouraging myopic imitation.
} 
selling only to its captive consumers. Then, $\pi_{i t}=1$ means that subject $i$ earned the monopoly profit in period $t$.

Table 2 and figures 2 to 4 here

Table 3 reports estimates of the dynamic regression equation:

$$
\begin{gathered}
\ln p_{i t}=\beta_{0}+\beta_{1} \ln p_{i, t-1}+\beta_{2} \ln \pi_{i, t-1}+\beta_{3} \ln r p_{i, t-1}+\beta_{4} t+\beta_{5} i 3_{i}+\beta_{6} c 6_{i}+ \\
\beta_{7} i 6_{i}+u_{i}+\epsilon_{i t}
\end{gathered}
$$

where $r p_{i, t-1}$ is the previous period logarithm of average rival prices, $\pi_{i, t-1}$ is the past period profits of subject $i, i i_{i}, c 6_{i}$ and $i 6_{i}$ are treatment dummy variables, $u_{i}$ is an unobserved variable capturing time-invariant heterogeneity and $\epsilon_{i t}$ is a regression disturbance.

Table 3 here

We also present in Table 4 estimates of the dynamic linear probability model:

$$
\begin{gathered}
\ln m p_{i t}=\alpha_{0}+\alpha_{1} \ln m p_{i, t-1}+\alpha_{2} \ln \pi_{i, t-1}+\alpha_{3} \ln r p_{i, t-1}+\alpha_{4} t+\alpha_{5} i 3_{i}+\alpha_{6} c 6_{i}+ \\
\alpha_{7} i 6_{i}+v_{i}+\omega_{i t}
\end{gathered}
$$

where $m p_{i, t-1}$ is an indicator taking the value 1 if subject $i$ sets the monopoly price in period $t$, and 0 otherwise, $v_{i}$ stands for unobserved time-invariant subject heterogeneity, and $\omega_{i t}$ is a regression disturbance. Thus, this approach accounts for the substantial individual heterogeneity present in the data and the underlying dynamics.

Table 4 here 
The estimates in Tables 3 and 4 correspond to the GMM dynamic panel estimators according to Arellano and Bond (1991), Arellano and Bover (1995), and Blundell and Bond (1998). These estimators are appropriate for a sampling scheme of small $T$-large $N$ but our sample consists of 180 individuals acting during 50 consecutive periods. So, we use stacked instruments as in Arellano (2003).

We use three lags, $\ln r p_{i}, \ln p_{i, t-1}, \ln \pi_{i, t-1}$ and three lags of $\ln r p_{i}, \ln m p_{i, t-1}, \ln \pi_{i, t-1}$ in Tables 3 and 4 , respectively. For the levels equation, the instruments are a constant, $t, i 3_{i}, c 6_{i}$ and $i 6_{i}$. Models with two lags of the regressors reveal that additional lags are not significant. The specification tests do not detect problems of serial correlation, suggesting that our simple specifications (4) and (5) adequately capture the dynamics in our data. The specification tests $m_{1}$, and $m_{2}$ are the Arellano and Bond (1991) tests for autocorrelation of order 1 and 2. If $\varepsilon_{i t}$ or $\omega_{i t}$ are not serially correlated, $m_{1}$ should reject the null, but $m_{2}$ should not reject. $J$ is the Hansen's test of overidentifying restrictions. The $F$ in the last row tests the joint significance of the second lag of the regressors.

Table 2 shows that 6-firm markets yield profits which are very close to monopoly pricing. On the contrary, 3-firm markets yield profits which are lower than the safe profit of monopoly pricing. We cannot reject the hypothesis that the average profit equals 1 in any of the treatments. The dispersion of profits is increasing in the 
number of firms present in the market and is greater under incomplete than under complete sampling. Figure 4 shows the evolution of average profits per treatment. There is no systematic temporal pattern or trend and we cannot reject the hypothesis of serial independence according to the results of run tests. From simple inspection of Table 2 and Figures 2 and 3, note that the means, standard deviations and the distributions of prices significantly deviate from the corresponding theoretical ones.

On the contrary, from Figure 5 observe that the counter-clockwise rotation of price distributions resulting from a decrease in the number of firms and the size of the index is in accordance with the comparison of cumulative distributions across treatment pairs C3-I3 and C6-I6. Although this can be a confirmation of the Burdett and Judd (1983) and Varian (1980) models’ predictions, we reject hypotheses H1 and H2 through a number of different tests. Among them, the estimates of treatment dummy coefficients in the model of individual prices in Table 3 indicate that the ranking of mean prices corresponding to treatments with different firm numbers and index sizes is the contrary to the theoretical one. That is, a decrease in the size of the index of prices on the search engine and a decrease in the total number of firms in the industry would both lead to higher average prices, providing evidence for the collusive effect in Jansen and Moraga-González (2004). 
We analyze now the monopoly pricing and its evolution. Figure 6 contains price distributions under each treatment. From the graphs, observe that price distributions are bimodal. One mode is monopoly pricing, whereas a second mode corresponds to interior prices.

Figure 6 here

The frequency of monopoly pricing in treatments C3, I3 and I6 (17\%, 14\% and $13 \%$ respectively) is much larger than the model predicts $(1.83 \%, 0.05 \%$ and 6.3\%, respectively). Monopoly pricing in C6 is approximately the same as in the theoretical prediction (17.56\% against the theoretical frequency of 18\%). Complete coverage treatments, C3 and C6, yield higher frequencies of monopoly pricing (17\% and $18 \%$, respectively) than the corresponding incomplete coverage treatments, which is compatible with H4. On the contrary, changes in the total number of firms (from C3 to C6 and from I3 to I6) produce insignificant effects on the frequency of monopoly pricing, which contradicts H3. However, a more rigorous test of H3 and H4 can focus on the significance of treatment dummies in the Probit model of monopoly pricing. The estimates in Table 4 reject both $\mathrm{H} 3$ and $\mathrm{H} 4$ against the alternative that the frequency of monopoly pricing does not vary with the total number of firms in the market and the number of firms on the search engine. 
Figure 2 shows period average prices. Regarding the last hypothesis, H5, the general pattern is that average prices steadily decrease in the first twenty periods and then tend to stabilize. The initial decrease is more pronounced in treatments C6 and I6. Indeed in treatment C6, average prices do not stabilize before period 30. Figure 2 also shows the price series excluding monopoly prices $(p=1)$. The evolution of interior prices is characterized by a strong decreasing trend. On Figure 3, observe some interesting patterns with respect to the frequency with which $p=1$. In general, the frequency of monopoly pricing steadily increases in treatments C3 and I3. There are also increases in treatments C6 and I6, but the pattern is less clear. The estimates of the linear probability model for monopoly pricing, equation (5), in Table 4 reveal that there is an increasing trend in the frequency of monopoly pricing along the 50 periods of a session. At the same time, the estimates of the individual pricing model (4) in Table 3 show that, overall, prices present a declining trend. This implies that interior prices present a strongly decreasing tendency. Also, given the significance of the lagged own strategy coefficients, both the overall and the monopoly pricing models reject the hypothesis of independence of individual strategies over time, which is a rejection of $\mathrm{H} 5$.

The pricing model confirms the existence of prices compatible with Cournot best responses. A firm's price in a given period positively relates to the average price 
of rival firms in the previous period. The corresponding model with two lags rejects the reaction to rival prices in periods before the last. Also, a period's price is lower following a period of low earnings, while further lags of a firm's own profit were also non-significant. Intuitively, this finding implies that firms failing to be the most competitive among those in the index are more likely to adopt a higher price in the following period. In fact, in that case, a rational player should then revert to monopoly pricing. The estimates of the monopoly pricing model confirm exactly this conjecture. The lower the average of rival prices, the more likely it is that a firm adopts monopoly pricing in the next period.

Thus, a firm engages in competitive pricing trying to be the cheapest among those on the search engine. In that effort, it reacts to rival past prices in the form of Cournot best responses. The firm will frequently fail to be the cheapest. In that case, it abandons competitive prices in favor of monopoly pricing. Such cycles coexist with an increasing trend in the frequency of monopoly pricing and a decreasing trend of interior prices.

\section{Conclusions}

This paper reports experiments which relate to the models by Burdett and Judd (1983) and Varian (1980). The data provide limited support for the static predictions 
of the two models. However, the data analysis reveals some novel underlying

dynamic phenomena.

First, price distributions are bimodal. One mode corresponds to monopoly

pricing and the other to interior price dispersion. The frequency of monopoly pricing

remains invariant across treatments. Interior prices present a decreasing trend,

whereas the frequency of monopoly pricing increases over time. Also, firms raise

prices in response to higher rival prices in the past and are more likely to adopt

monopoly pricing following a period of low profits. On the contrary, they are more

likely to set interior prices in response to rivals adopting monopoly pricing in the

previous period. These patterns are compatible with Cournot best responses and price

cycles caused by firms' switching from interior to monopoly pricing and vice versa.

The conjecture by Jansen and Moraga-González (2004) is confirmed by

interior prices, because monopoly pricing is not affected by the number of firms in the market and the sample on the search engine. Therefore, in markets with search, some prices will decrease over time, while, at the same time, the frequency of monopoly pricing will increase. Our findings have important implications for firms' pricing strategies in search markets, and especially for new entrants who should expect dispersion to persist due to the increase in the frequency of monopoly prices and the decrease of more competitive ones. 
We have focused here on the role of a single search engine. However, it is

often the case that there are several competing search engines. Future research could study the role of competition among different platforms to check the robustness of our findings under this setup. Also, our model has assumed a homogeneous product market. While it is interesting to consider differentiated products, our focus has shown that price dispersion does not necessarily depend on differences among the products sold in the market.

\section{References}

Arellano, M. (2003). Panel data econometrics. Oxford University Press.

Arellano, M., and Bond, S. (1991). Some tests of specification for panel data: Monte Carlo evidence and an application to employment equations. Review of Economic Studies, 58, 277-297.

Arellano, M., and Bover, O. (1995). Another look at the instrumental variables estimation of error components models. Journal of Econometrics, 88, 29-51.

Baye, M., D. Kovenock, and de Vries, C. G. (1992). It Takes Two to Tango: Equilibria in a Model of Sales. Games and Economic Behavior, 4, 493-510. 
Baye, M. and Morgan, J. (2001). Information gatekeepers on the Internet and the compe- titiveness of homogeneous product markets. American Economic Review, 91, 3, 454-474.

Baye, M. and Morgan, J. (2004). Price dispersion in the Lab and on the Internet: theory and evidence. The RAND Journal of Economics, 35, 448-466.

Benaïm, M., Hofbauer, J., and Hopkins, E. (2009). Learning in games with unstable equilibria. Journal of Economic Theory, 144, 1694-1709.

Blundell, R., and Bond, S. (1998). Initial conditions and moment restrictions in dynamic panel data models. Journal of Econometrics, 87, 115-143.

Brynjolfsson, E., and Smith, M. (2000). Frictionless commerce? A comparison of Internet and conventional retailers. Management Science, 46, 4, 563-585.

Burdett, K. and Judd, K. (1983). Equilibrium price dispersion. Econometrica, 51, 955- 969.

Cameron, A.C. and Trivedi, P.K. (2005). Microeconometrics. Methods and applications. Cambridge University Press.

Cason, T. and Datta, S. (2006). An experimental study of price dispersion in an optimal search model with advertising. International Journal of Industrial Organization, 24, 639- 665. 
Cason, T.N. and Friedman, D. (2003). Buyer search and price dispersion: a laboratory study. Journal of Economic Theory, 112, 232-260.

Cason, T.N., Friedman, D., and Wagener, F. (2005). The dynamics of price dispersion or Edgeworth variations. Journal of Economic Dynamics and Control, 29, 801-822.

Diamond, P. (1971). A model of price adjustment. Review of Economic Theory, 3, 156-178.

García-Gallego, A., Georgantzís, N., Pereira P., and Pernías, J.C. (2004). Risk attitudes and Internet search engines: theory and experimental evidence. Working Paper 04-03, NET Institute.

Hopkins, E. and Seymour, R. (2002). The stability of price dispersion under seller and consumer Learning. International Economic Review, 43, 1157-1190.

Iyer, G. and Pazgal, A. (2000). Internet shopping agents: virtual co-location and competition. Marketing Science, 22, 85-106.

Janssen, M. C. W. and Moraga-González, J.L. (2004). Strategic pricing, consumer search and the number of firms. Review of Economic Studies, 71, 1089-1118.

Kocas, C. and Kiyak, T. (2006). Theory and evidence on pricing by asymmetric oligopolies. International Journal of Industrial Organization, 24, 83-105. 
Morgan, J., Orzen, H., and Sefton, M. (2006). An experimental study of price dispersion. Games and Economic Behavior, 54, 134-158.

Orzen, H. (2005). Counterintuitive Number Effects in Experimental Oligopolies. Experimental Economics, 11, 390-401.

Rosenthal, R. (1980). A model in which an increase in the number of sellers leads to a higher price. Econometrica, 48, 1575-1579.

Shapley, L. (1964). Some topics in two person games. In Drescher (ed.). Advances in Game Theory. Princeton: Princeton University Press.

Stahl, D. (1989). Oligopolistic pricing with sequential consumer search. American Economic Review, 79, 700-712.

Varian, H. (1980). A model of sales. American Economic Review, 70, 651-659.

Warnick, J. E. and Hopkins, E. (2006). A Simple Test of Learning Theory. University of Edinburgh, ESE Discussion Paper 153.

\section{Tables}

Table 1. Design parameters

\begin{tabular}{lrrrrrrr}
\hline Treatment & $n$ & $K$ & $\varnothing$ & $\lambda$ & Price Mean (St. dev.) & Min. Price & $\operatorname{Pr}(p=1)$ \\
\hline C3 & 3 & 3 & 1 & $1 / 2$ & $0.60(0.25)$ & 0.25 & $1.83 \%$ \\
I3 & 3 & 2 & $2 / 3$ & $1 / 2$ & $0.55(0.18)$ & 0.33 & $0.05 \%$ \\
C6 & 6 & 6 & 1 & $1 / 2$ & $0.70(0.31)$ & 0.42 & $17.56 \%$
\end{tabular}


Table 2: Descriptive statistics: prices and profits

\begin{tabular}{lllll}
\hline Treatment & All Prices & Interior Pricing & Mon. Pricing & Profits \\
\hline C3 & $0.56(0.04)$ & $0.47(0.07)$ & $0.17(0.06)$ & $0.89(0.24)$ \\
I3 & $0.55(0.05)$ & $0.48(0.05)$ & $0.14(0.05)$ & $0.86(0.36)$ \\
C6 & $0.47(0.05)$ & $0.35(0.08)$ & $0.18(0.05)$ & $0.95(0.35)$ \\
I6 & $0.49(0.07)$ & $0.41(0.08)$ & $0.13(0.05)$ & $1.02(0.56)$ \\
\hline
\end{tabular}

Standard deviations in parentheses; Mon. Pricing: frequency with which a subject sets $p=1$. Interior pricing: $p \neq 1$

Table 3: Price Regressions

\begin{tabular}{ccc}
\hline & $G M M(1$ lag $)$ & $G M M(2$ lags $)$ \\
\hline $\ln p_{i, t-1}$ & $0.1111(0.0316)^{* * *}$ & $0.0823(0.0477)^{*}$ \\
$\ln p_{i, t-2}$ & & $-0.0212(0.0292)$ \\
$\ln r p_{i, t-1}$ & $0.1646(0.0353)^{* * *}$ & $0.1696(0.0363)^{* * *}$ \\
$\ln r p_{i, t-2}$ & & $0.0148(0.0243)$ \\
$\ln \pi_{i, t-1}$ & $-0.0293(0.0152)^{*}$ & $-0.0471(0.0201)^{* *}$ \\
$\ln \pi_{i, t-2}$ & & $-0.0161(0.0142)$ \\
\hline
\end{tabular}




\begin{tabular}{ccc}
\hline$t$ & $-0.0044(0.0008)^{* * *}$ & $-0.0044(0.0009)^{* * *}$ \\
$i 3_{i}$ & $0.0457(0.0560)$ & $0.0572(0.0598)$ \\
$i 6_{i}$ & $-0.3010(0.0859)^{* * *}$ & $-0.3226(0.0942)^{* * *}$ \\
Const. & $-0.1805(0.0606)^{* * *}$ & $-0.1904(0.0666)^{* * *}$ \\
Specification tests $(p-v a l u e s)$ & $-0.4667(0.0684)^{* * *}$ \\
$m_{1}$ & $-0.4294(0.0536)^{* * *}$ & \\
$m_{2}$ & 0.000 & 0.000 \\
$J$ & 0.198 & 0.856 \\
F 2 & & 0.447 \\
\hline lag & & \\
\hline
\end{tabular}

Two-step system GMM estimates of equation (4). The dependent variable is $\ln p_{i t}$.

Table 4: Monopoly pricing regressions

\begin{tabular}{lll}
\hline & $G M M(1$ lag $)$ & GMM (2 lags) \\
\hline $\ln m p_{i, t-1}$ & $0.0726(0.0351)^{* * *}$ & $0.0495(0.0529)$ \\
$\ln m p_{i, t-2}$ & & $-0.0117(0.0381)$ \\
$\ln r p_{i, t-1}$ & $-0.0326(0.0173)^{*}$ & $-0.0385(0.0182)^{* *}$ \\
$\ln r p_{i, t-2}$ & & $-0.0204(0.0126)$ \\
$\ln \pi_{i, t-1}$ & $-0.0251(0.006)^{* * *}$ & $-0.0313(0.0120)^{* * *}$ \\
\hline
\end{tabular}




\begin{tabular}{|c|c|c|}
\hline $\ln \pi_{i, t-2}$ & & $-0.0062(0.0080)$ \\
\hline$t$ & $0.0014(0.0004)^{* * *}$ & $0.0013(0.0005)^{* * *}$ \\
\hline$i 3_{i}$ & - 0.0176 (0.0499) & $-0.0266(0.0513)$ \\
\hline$c 6_{i}$ & $0.0347(0.0556)$ & 0.0389 (0.0569) \\
\hline$i 6_{i}$ & - $0.0217(0.0469)$ & $-0.0243(0.0477)$ \\
\hline Const. & $0.0788(0.0411)^{*}$ & $0.0748(0.0427)^{*}$ \\
\hline \multicolumn{3}{|c|}{ Specification tests (p-values) } \\
\hline$m_{1}$ & 0.000 & 0.000 \\
\hline$m_{2}$ & 0.707 & 0.674 \\
\hline$J$ & 0.112 & 0.160 \\
\hline$F 2^{\text {nd }} \operatorname{lag}$ & & 0.135 \\
\hline
\end{tabular}

Two-step system GMM estimates of equation (5). The dependent variable is $\ln m p_{i t}$.

Figures

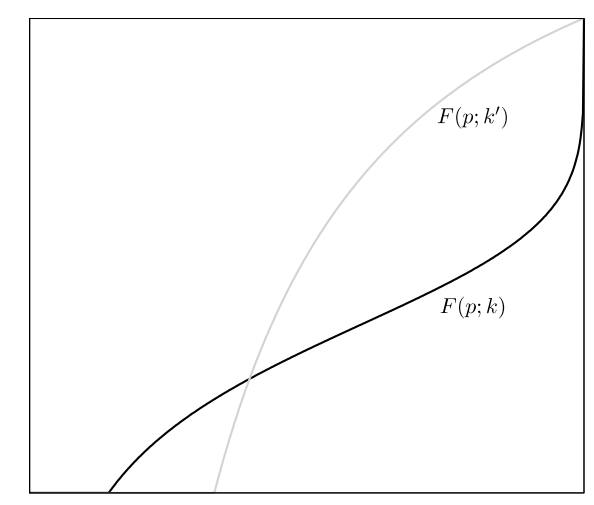


Figure 1. Price rotation when $k$ decreases to $k$ '

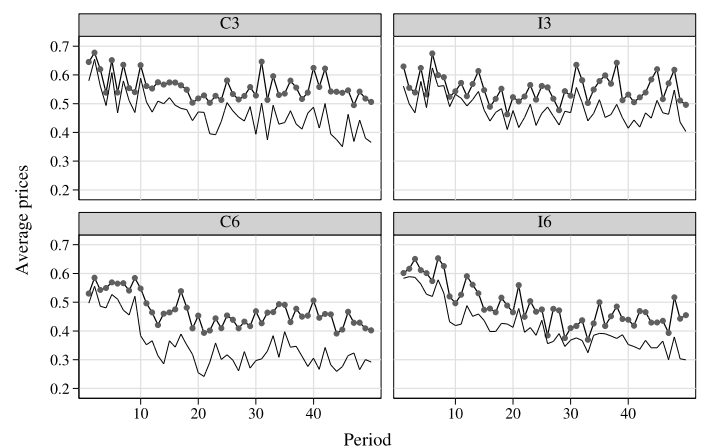

Figure 2. Evolution of prices and interior prices

Figure 3. Evolution of the frequency of monopoly pricing

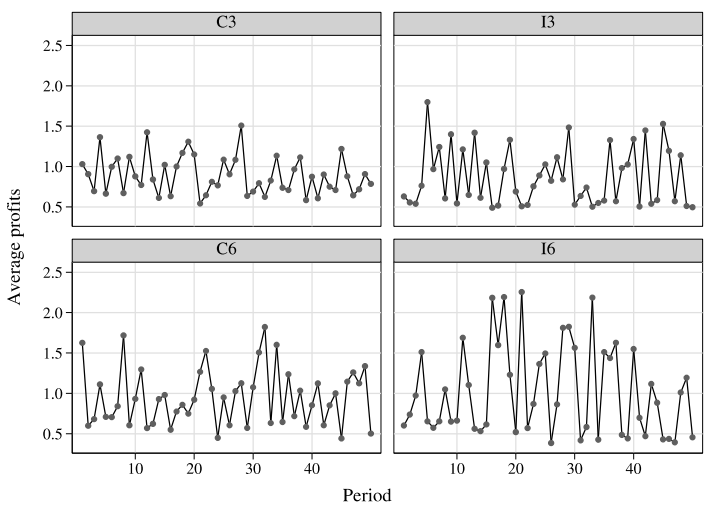

Figure 4. Evolution of average profits 


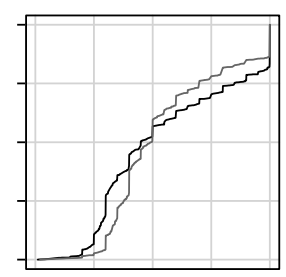

Figure 5. Observed prices. The dark line: treatment with a larger index size

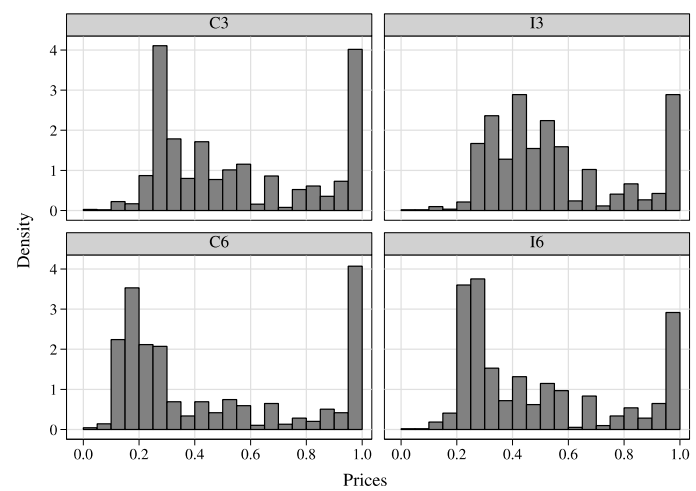

Figure 6. Histograms of price distributions, per treatment 